\title{
Utility of Multi-Theory Model (MTM) to Explain the Intention for PAP Adherence in Newly Diagnosed Sleep Apnea Patients
}

This article was published in the following Dove Press journal: Nature and Science of Sleep

\author{
Manoj Sharma' \\ Anuj Chandra ${ }^{2}$ \\ Ryan Toth ${ }^{2}$ \\ Vinayak K Nahar ${ }^{3,4}$ \\ 'Department of Environmental \& \\ Occupational Health, School of Public \\ Health, University of Nevada, Las Vegas, \\ NV, USA; ${ }^{2}$ Advanced Center for Sleep \\ Disorders, Chattanooga, TN, USA; \\ ${ }^{3}$ Department of Dermatology, School of \\ Medicine, University of Mississippi \\ Medical Center, Jackson, MS, USA; \\ ${ }^{4}$ Department of Preventive Medicine, \\ School of Medicine, University of \\ Mississippi Medical Center, Jackson, \\ MS, USA
}

Purpose: The objective of this study was to assess the utility of a fourth-generation multitheory model (MTM) in explaining the intention for initiation and sustenance of PAP adherence among newly diagnosed sleep apnea patients.

Patients and Methods: For this cross-sectional study, data were collected at a private sleep center located in the Southeastern United States. A total of 138 newly diagnosed patients with sleep apnea who had been prescribed PAP therapy completed a valid and reliable 41item MTM instrument. Stepwise multiple regression modeling was conducted to assess MTM based explanatory variables of PAP adherence in this study sample.

Results: MTM constructs namely participatory dialogue $(\beta=0.17, p=0.014)$, behavioral confidence $(\beta=0.48, p<0.001)$, and changes in the physical environment $(\beta=0.26, p=$ 0.001 ) were statistically significant predictors of the intention for initiation of PAP therapy and accounted for $53.5 \%$ of the variance. Emotional transformation $(\beta=0.57, p<0.001)$, changes in the social environment $(\beta=0.16, p=0.016)$, and practice for change $(\beta=0.16$, $p=0.047)$ were statistically significant predictors of the intention for sustenance of PAP therapy and accounted for $60.6 \%$ of the variance.

Conclusion: The MTM was found to be a promising theoretical model in explaining the intention for initiation and sustenance of PAP therapy.

Keywords: sleep apnea, positive airway pressure, compliance, predictors, multi-theory model

\section{Introduction}

Sleep apnea syndrome consists of recurring bouts of partial or complete upper airway obstruction during sleep with the presence of daytime hypersomnolence. ${ }^{1}$ In the United States, obstructive sleep apnea affects $17 \%$ of women and $34 \%$ of men and has a comparable prevalence in other nations. ${ }^{2}$ Sleep apnea has been identified as an independent risk factor for cardiovascular disease, hypertension, daytime sleepiness, stroke, motor vehicle accidents, lower quality of life, ${ }^{3}$ and altered glucose metabolism, ${ }^{4}$ thus placing a high value on optimizing treatment modalities.

Common treatment methods for sleep apnea include positive airway pressure (PAP) therapy, the use of oral appliances such as mandibular repositioning appliances, surgical interventions, behavioral changes, or a combination of some or all of these. ${ }^{5}$ PAP therapy is the gold standard and has been shown to be more effective compared to treatments such as positional therapy and other conservative treatment methods. ${ }^{6}$ However, PAP therapy does not cure sleep apnea so treatment with it
Correspondence: Vinayak K Nahar Department of Dermatology, School of Medicine, University of Mississippi Medical Center, 2500 North State Street - L216, Jackson, MS, 39216, USA

Tel + I 60I 4955876

Fax + I 60I 984 II50

Email naharvinayak@gmail.com 
must be ongoing and adherence to it is a crucial component of successful treatment for sleep apnea.

PAP adherence has been defined at $>4$ hours per night for $70 \%$ of nights, though the effectiveness of the 4 hour benchmark has been contested in favor of a minimum of 5 hours. ${ }^{7}$ Regardless, it is noted that PAP therapy should ideally be used for the entire duration of sleep, as is often prescribed. Studies have shown adherence issues in both children and adults with average usage below 5 hours/ night. $^{7-9}$ A systematic review of 82 papers in 2016 found the continuous positive airway pressure (CPAP) nonadherence rate based on a 7-hour/night sleep time over a twenty-year time frame as $34.1 \% .{ }^{10}$ It is apparent, then, that interventions that promote PAP adherence are of high clinical value.

Promoting CPAP adherence requires a multifaceted approach. A large review of CPAP adherence conducted by Sawyer et al identified four overarching factors that affected adherence: (1) titration treatment procedure (autotitrating CPAP), (2) patient and disease characteristics (race, socio-economic status, disease severity, sleepiness, and upper airway patency) (3) technology/device-related factors (heated humidification, claustrophobia, and flexible pressure), and (4) psychosocial factors (self-efficacy, outcome expectations, decisional balance, active coping style, disease-specific risk perception, disease and treatment specific knowledge, and presence of bed partner). ${ }^{7}$ The continuous advancements in technology have helped accommodate adherence-limiting factors like low nasal cross-sectional area, ${ }^{11}$ side effects such as dry mouth, and discomfort with the mask or nasal appliance. ${ }^{12}$ However, the psychosocial factors on adherence are just now beginning to be understood. Factors such as low socioeconomic status and living alone negatively impact adherence. $^{13,14}$ The costs associated with buying CPAP machine are also a barrier for those without insurance coverage or from lower socio-economic status. ${ }^{15}$ Therefore, understanding the unique psychological and cultural background of a patient may optimize PAP adherence.

Many interventions exist to promote adherence, including pharmacological, technological, and psychosocial, but it has been noted that these have been ineffective or inconclusive at best. ${ }^{7}$ Hoy et al demonstrated that an intensive, multidimensional approach showed significant adherence improvement, ${ }^{16}$ but the resource demands required for such an intervention may limit its clinical applicability. ${ }^{7}$ Being able to explain which patients are less likely to initiate PAP therapy and/or sustain it is of value for risk stratification and resource management, but very few theoretical models have been used in the literature to model PAP adherence such as Health Belief Model, ${ }^{17}$ and social cognitive theory and transtheoretical model combined. ${ }^{18,19}$ Recently, Bakker and colleagues have advocated the use of theory-driven behavioral approaches for increasing PAP adherence. ${ }^{20}$ To date, there are few modalities to explain those who are unlikely to be adherent, which, a novel fourth-generation model, the multi-theory model (MTM) of health behavior change may be able to accomplish.

The multi-theory model (MTM) of health behavior change is a parsimonious theory that incorporates cognitive, conative, and environmental empirically tested components to initiate and maintain health behavior change. $^{21,22}$ MTM has been shown to be successful at predicting behavior change (both initiation and sustenance) in several cross-sectional studies ${ }^{23-26}$ and experimental studies for physical activity promotion in African American women, ${ }^{27}$ increasing fruit and vegetable consumption in African American women, ${ }^{28}$ and reducing water-pipe smoking in Iranian adolescents. ${ }^{29}$ It is in this context that the present study's objective was to examine the utility of MTM in explaining the intention for initiation and sustenance of CPAP/Bilevel Positive Airway Pressure (BiPAP) adherence among newly diagnosed sleep apnea patients.

\section{Theoretical Framework}

MTM is unique in that it is specific to health behavior and differentiates between behavior initiation and behavior sustenance. The MTM constructs which influence the initiation of behavior change include participatory dialogue, behavioral confidence, and changes in the physical environment. $^{21}$ Their relationships can be seen in Figure 1. The participatory dialogue construct builds on the pros and cons of the transtheoretical model and perceived benefits/ barriers in the health belief model by emphasizing a mutual exploration dialogue. ${ }^{21}$ Behavioral confidence is derived for Bandura's self-efficacy and Ajzen's perceived behavioral control. ${ }^{21}$ It differs in that the source of behavioral confidence includes external sources, and the conceptualization pertains to future goals rather than focusing on the present. ${ }^{21}$ The construct of changes in the physical environment entails making changes to obtainability, availability, accessibility, convenience, and readiness of physical resources. $^{21}$ 


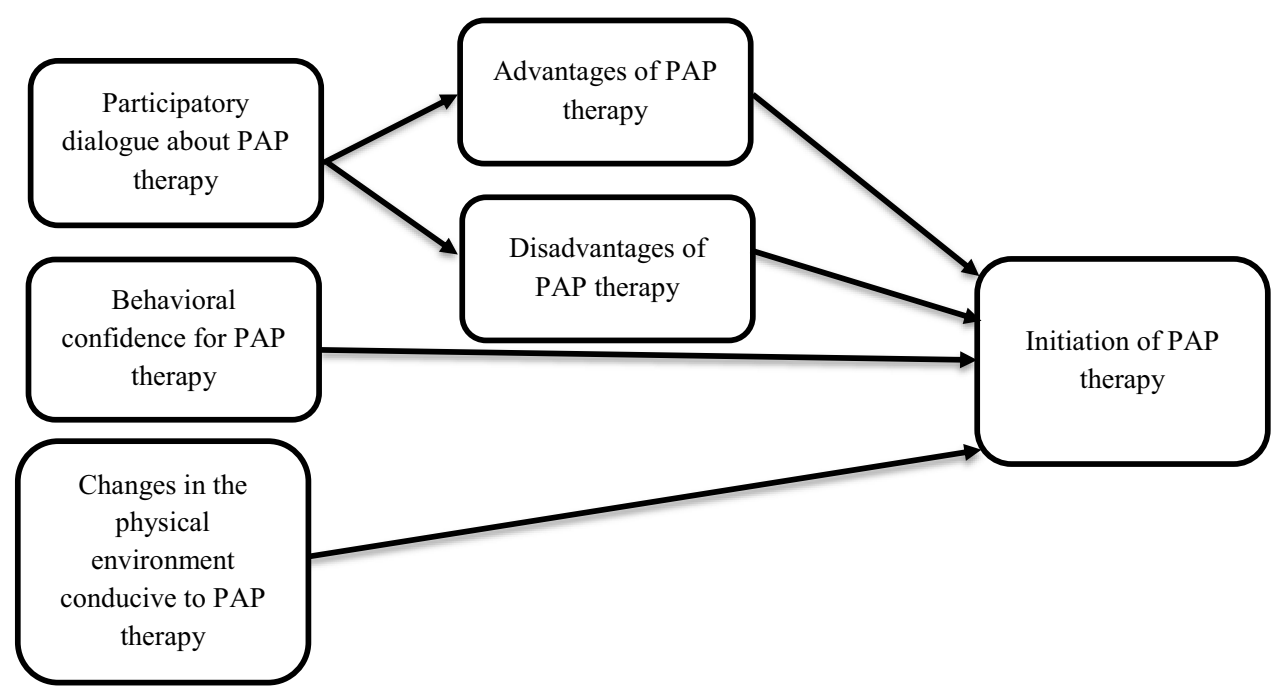

Figure I Constructs of initiation of health behavior change in multi-theory model (MTM).

The constructs which focus on the sustenance of health behavior change include emotional transformation, practice for change, and change in the social environment. ${ }^{21}$ Their relationships can be seen in Figure 2. Emotional transformation is a method to convert emotions toward changing health behavior, directing oneself toward a goal despite hindrances. ${ }^{21}$ Practice for change is a construct which entails actively reflecting on the progression of behavior change and addressing barriers as they arise. ${ }^{21}$ Similar to changes in the physical environment, the final construct focuses on creating social support from the environment. ${ }^{21}$

\section{Patients and Methods Design}

The design used for this study was cross-sectional. This design offers the advantages of gathering data easily and quickly. It provides a snapshot in the time of the study variables. As a result, it suffers from the disadvantage that temporal (time sequence) association between independent and dependent variables cannot be ascertained. However, based on the theoretical premise of the MTM constructs preceding the intentions for PAP therapy adherence this design was chosen as an appropriate pragmatic approach with limitations. As explained earlier, the independent variables for the initiation model were the constructs of MTM namely participatory dialogue, behavioral confidence and changes in the physical environment with the dependent variable as being the intention for initiation of PAP therapy in the upcoming week. The independent variables for the sustenance (maintenance) model were the MTM constructs of emotional transformation, practice for change, and changes in the social environment with the

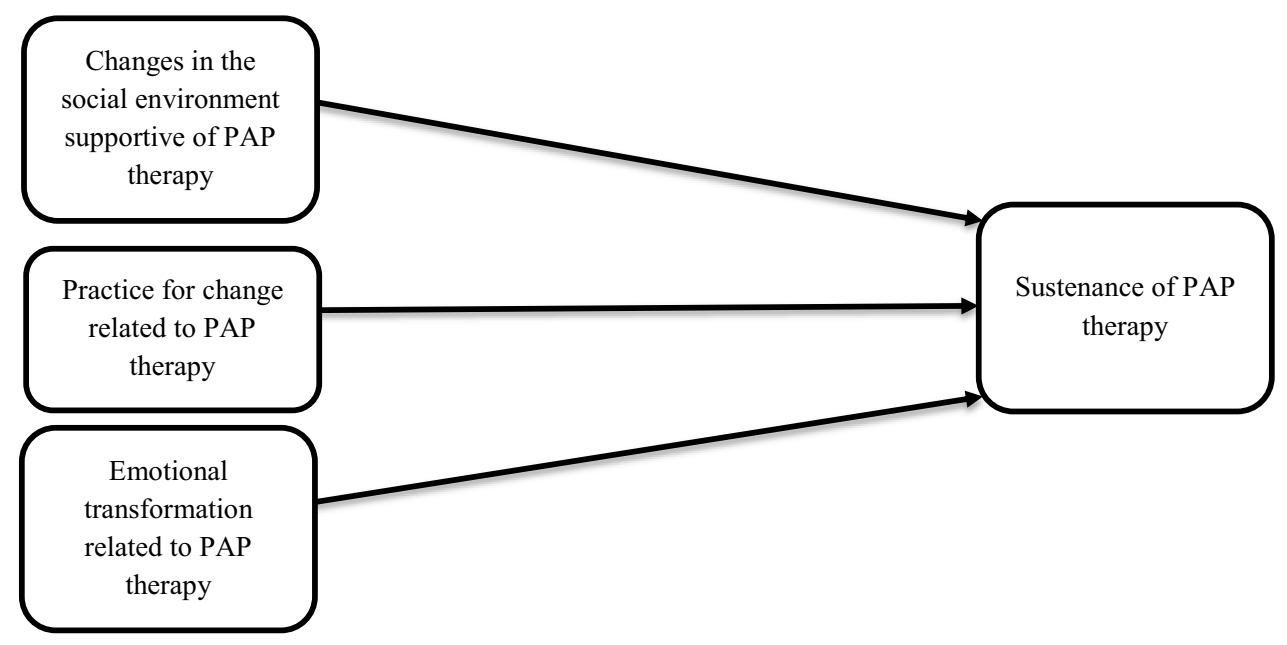

Figure 2 Constructs of sustenance of health behavior change in multi-theory model (MTM). 
dependent variable being the intention to use PAP therapy every night from now on. Since the participants had been recruited following a sleep study, so the covariate of experience with sleep study was also added to each of the models. Acclimatization to the CPAP during the titration night is usually an important factor in the decision for the patient to use PAP therapy or choose another alternate approach. Therefore, the experience with sleep study was used as a covariate. ${ }^{30,31}$ Ethics approval was obtained from the Institutional Review Board at the Lincoln Memorial University.

\section{Population and Sampling}

The intended population for this study consisted of the newly diagnosed patients with sleep apnea who had been prescribed PAP therapy by their health care providers. Since the purpose of this study was to test the theoretical paradigm a quota sample was considered sufficient. A mid-sized private sleep center located in the Southeastern United States was approached to recruit the sample. The sample size was calculated using G*Power (Heinrich-Heine-Universität Düsseldorf). ${ }^{32}$ An $\alpha$ of 0.05 , a power of 0.80 , four predictors in each of the initiation and sustenance model, and an estimated effect size of 0.10 (medium) yielded a sample size of 125. Participants were recruited until complete data from 125 usable questionnaires were collected. This sample size was also deemed sufficient for internal consistency reliability estimation using Cronbach's alpha and construct validation using confirmatory factor analysis. ${ }^{33}$

\section{Instrumentation}

A 41-item MTM instrument (Supplementary Material: Measuring Change In CPAP/BIPAP Adherence) was developed by the lead researcher based on a review of the literature and constructs of MTM which was then validated for face and content validity in two rounds by a panel of six experts who were University Professors and had expertise in one or more areas of instrument development, sleep research or theory. The validation process entailed sending each expert the instrument along with operational definitions of all terms and was completed in two rounds. The first two items on the instrument were screening items and asked the participants whether they had recently been diagnosed with sleep apnea by a health care provider and if they had recently been prescribed CPAP/BiPAP machine. If their answer was in the affirmative only then could they complete the remaining survey. If they did not meet these two criteria they were excluded from the study.

The Flesch-Kincaid Reading level of the scale was 6.3 or $<$ seventh grade and the Flesch Reading Ease score was 72.1. The internal consistency reliability coefficients of the subscales and entire scale were computed using Cronbach's alpha on the study sample. For construct validation, the criteria of Eigenvalue greater than 1 and factor loadings greater than 0.32 were established and confirmatory factor analysis using maximum likelihood method was employed on the subscale data from the study sample. $^{33}$

\section{Data Collection and Ethics}

Institutional Review Board (IRB) approval from the institution of the last author was obtained before the study (Protocol \#: 692 V.2). This study was conducted in accordance with the Declaration of Helsinki. Data were collected at the sleep center under the supervision of the second author of the study. Written informed consent was obtained from all the participants with voluntary participation and the ability to withdraw from completing the questionnaire at any time. Only participants who met the inclusion criteria as described earlier were included in the data collection.

\section{Data Analyses}

All data were analyzed using SPSS, Version 25.0. Descriptive statistics for metric variables were summarized by calculating means and standard deviations while frequencies and percentages were reported for categorical variables. To assess statistically significant associations between covariates (age, gender, race/ethnicity, education, work status, income, and sleep study experience) and dependent variables (intention for initiation of PAP therapy and intention for the sustenance of PAP therapy), Pearson Product-Moment correlations, one-way analysis of variance (ANOVA), and independent samples $t$ tests were performed. Sleep study experience showed statistically significant associations with both the dependent variables. For inferential model building, stepwise multiple regression modeling was utilized. As per the SPSS default, the a priori criteria in stepwise regression modeling of the probability of the $F$ to enter the independent variable in the model was chosen as $\leq$ to 0.05 and for removing the independent variable as greater than and equal to 0.10 . For both the initiation model and 
sustenance model, sleep study experience was used as a covariate.

\section{Results}

A total of 138 participants responded to the questionnaire. The missing data on different variables ranged from 3 to 14 responses or $<10 \%$. There were $86(62.3 \%)$ males and $49(35.5 \%)$ females in the dataset with no one marking as other. The mean age of the respondents was 51.3 years (s. d. = 14.4). The majority of the respondents were Caucasian Americans (80\%) and nearly 32\% had completed high school and another $31 \%$ had completed college or graduate degree. A total of $61 \%$ worked for pay and those who worked had a mean of 44.6 hours (s.d. $=12.8$ ). The descriptive distribution of socio-demographic variables is depicted in Table 1 .

The descriptive statistics (means and standard deviations) of all study variables and Cronbach's alpha of all subscales are reported in Table 2. The Cronbach's alphas (which are an indication of internal consistency reliability) ranged from 0.77 to 0.98 and were acceptable. ${ }^{33}$ In addition, for construct validation, all subscales were subjected to confirmatory factor analysis using the maximum likelihood method. No rotation was needed and all subscales met the criteria of Eigenvalues over 1.0, scree plots with the elbow at factor 1 and factor loadings over 0.32 confirming one-factor solutions or indicative of single construct for each subscale. ${ }^{33}$

For predictive modeling, stepwise multiple regression was employed. Two models were built. For the first model which pertained to the intention for initiation of PAP therapy the independent variables were participatory dialogue, behavioral confidence and changes in the physical environment along with the experience of sleep study serving as a covariate. The results are summarized in Table 3. The model explained $53.5 \%$ of the variance in starting PAP therapy among newly diagnosed sleep apnea patients as a result of the significant constructs of behavioral confidence $(\beta=0.48, p<0.001)$, changes in the physical environment $(\beta=0.26, p=0.001)$, and participatory dialogue or advantages outweighing disadvantages $(\beta$ $=0.17, p=0.014$ ) while controlling for the sleep study experience.

For the second model which pertained to the intention for sustenance or maintenance of PAP therapy the independent variables were emotional transformation, practice for change, and changes in the social environment along with the experience of sleep study serving as a covariate.
Table I Socio-Demographic Characteristics of the Participants $(n=138)$

\begin{tabular}{|c|c|c|}
\hline & Mean (s.d.) & n (\%) \\
\hline Age (years) & $51.30(14.36)$ & \\
\hline \multicolumn{3}{|l|}{ Gender } \\
\hline Males & & $86(62.3 \%)$ \\
\hline Females & & 49 (35.5\%) \\
\hline Other & & $0(0.0 \%)$ \\
\hline \multicolumn{3}{|l|}{ Race/Ethnicity } \\
\hline White or Caucasian American & & III (80.4\%) \\
\hline Black or African American & & $17(12.3 \%)$ \\
\hline Asian American & & $2(1.4 \%)$ \\
\hline American Indian & & $0(0.0 \%)$ \\
\hline Hispanic American & & $2(1.4 \%)$ \\
\hline Other & & $3(2.2 \%)$ \\
\hline \multicolumn{3}{|l|}{ Education } \\
\hline $\begin{array}{l}\text { Some schooling but not completed } \\
\text { high school }\end{array}$ & & $8(5.8 \%)$ \\
\hline Completed high school or GED & & $44(31.9 \%)$ \\
\hline Some college & & 27 (19.6\%) \\
\hline Completed college/graduate & & $43(31.2 \%)$ \\
\hline degree & & \\
\hline Postgraduate degree & & $9(6.5 \%)$ \\
\hline Professional degree & & $4(2.9 \%)$ \\
\hline \multicolumn{3}{|l|}{ Work Status } \\
\hline Yes & & $84(60.9 \%)$ \\
\hline No & & $5 \mathrm{I}(37.0 \%)$ \\
\hline $\begin{array}{l}\text { Number of hours for those who } \\
\text { work }\end{array}$ & $44.60(12.78)$ & \\
\hline \multicolumn{3}{|l|}{ Yearly household income } \\
\hline$<\$ 50,000$ & & $50(36.2 \%)$ \\
\hline$\$ 50,001$ to $\$ 100,000$ & & 49 (35.5\%) \\
\hline$\$ 100,001$ to $\$ 150,000$ & & $15(10.9 \%)$ \\
\hline$\$ 150,001$ to $\$ 200,000$ & & $4(2.9 \%)$ \\
\hline$>\$ 200,000$ & & $2(1.4 \%)$ \\
\hline Prefer not to answer & & $10(7.2 \%)$ \\
\hline
\end{tabular}

Note: Due to missing data, the percentage of participants in each category of sociodemographic characteristics do not sum to $100 \%$.

The results are summarized in Table 4. The model explained $60.6 \%$ of the variance in the intention for maintaining PAP therapy among newly diagnosed sleep apnea patients as a result of the significant constructs of emotional transformation $(\beta=0.57, p<0.001)$, changes in the social environment $(\beta=0.16, p=0.016)$, and practice for change $(\beta=0.16, p=0.047)$ while controlling for the sleep study experience. 
Table 2 Descriptive Statistics of Study Variables and Cronbach's Alpha of Subscales

\begin{tabular}{|l|c|c|c|c|c|}
\hline Constructs & $\mathbf{n}$ & Possible Range & Observed Range & Mean (s.d.) & Cronbach's Alpha \\
\hline Sleep study experience & 131 & $0-12$ & $0-12$ & $6.18(3.11)$ & 0.83 \\
\hline Initiation & 132 & $0-4$ & $0-4$ & $3.11(1.13)$ & - \\
\hline Participatory dialogue: Advantages & 126 & $0-20$ & $0-20$ & $14.06(4.37)$ & 0.86 \\
\hline Participatory dialogue: Disadvantages & 124 & $0-20$ & $0-18$ & $7.44(3.58)$ & 0.77 \\
\hline Participatory dialogue: advantages - disadvantages score & 123 & $-20-+20$ & $-10-+18$ & $6.59(5.80)$ & - \\
\hline Behavioral confidence & 128 & $0-20$ & $0-20$ & $14.05(6.11)$ & 0.97 \\
\hline Changes in physical environment & 132 & $0-12$ & $0-12$ & $9.48(2.95)$ & 0.93 \\
\hline Entire initiation scale & & - & - & - & 0.86 \\
\hline Sustenance & 133 & $0-4$ & $0-4$ & $3.17(0.92)$ & - \\
\hline Emotional transformation & 133 & $0-12$ & $0-12$ & $9.25(3.11)$ & 0.98 \\
\hline Practice for change & 133 & $0-12$ & $0-12$ & $7.53(2.90)$ & 0.81 \\
\hline Changes in social environment & 132 & $0-12$ & $0-12$ & $8.28(3.42)$ & 0.80 \\
\hline Entire sustenance scale & & - & - & - & 0.91 \\
\hline Entire scale & & - & -12 & 0.91 \\
\hline
\end{tabular}

Table 3 Stepwise Multiple Regression Modeling Prediction of Intention of Initiation of PAP Therapy in Newly Diagnosed Sleep Apnea Patients

\begin{tabular}{|l|c|c|c|c|c|c|}
\hline Variables & $\mathbf{B}$ & $\mathbf{S E}_{\mathbf{B}}$ & $\boldsymbol{\beta}$ & $\mathbf{t}$ & $\boldsymbol{p}$-value & $\mathbf{9 5 \%} \mathbf{C l}$ \\
\hline Behavioral confidence & 0.087 & 0.013 & 0.489 & 6.748 & $<0.001$ & $0.061,0.112$ \\
\hline $\begin{array}{l}\text { Changes in the physical } \\
\text { environment }\end{array}$ & 0.091 & 0.026 & 0.263 & 3.480 & 0.001 & $0.039,0.143$ \\
\hline Participatory dialogue & 0.031 & 0.013 & 0.169 & 2.498 & 0.014 & $0.006,0.056$ \\
\hline$F(3,117)=46.952, p<0.001, R^{2}=0.546$, Adjusted $R^{2}=0.535$
\end{tabular}

Notes: Dependent variable is intention for initiation of PAP therapy; Independent variables are sleep study experience (non-significant), participatory dialogue, behavioral confidence and changes in the physical environment.

Abbreviations: $\mathrm{B}$, unstandardized coefficient; $\mathrm{SE}_{\mathrm{B}}$, standard error of the coefficient; $\beta$, standardized coefficient; $\mathrm{t}$, Student's t-test; $\mathrm{p}$, level of significance; $\mathrm{Cl}$, confidence interval.

Table 4 Stepwise Multiple Regression Modeling Prediction of Intention of Sustenance of PAP Therapy in Newly Diagnosed Sleep Apnea Patients

\begin{tabular}{|l|c|c|c|c|c|c|}
\hline Variables & $\mathbf{B}$ & $\mathbf{S E}$ & $\boldsymbol{\beta}$ & $\mathbf{t}$ & $\mathbf{P}$-value & $\mathbf{9 5 \%} \mathbf{C l}$ \\
\hline Emotional transformation & 0.168 & 0.024 & 0.569 & 6.997 & $<0.001$ & $0.120,0.215$ \\
\hline Changes in the social environment & 0.043 & 0.018 & 0.157 & 2.433 & 0.016 & $0.008,0.078$ \\
\hline Practice for change & 0.052 & 0.026 & 0.164 & 2.004 & 0.047 & $0.001,0.104$ \\
\hline$F(3,124)=66.025, p<0.001, R^{2}=0.615$, Adjusted $R^{2}=0.606$
\end{tabular}

Notes: Dependent variable is intention for sustenance of PAP therapy; Independent variables are sleep study experience (non-significant), emotional transformation, changes in the social environment and practice for change.

Abbreviations: $\mathrm{B}$, unstandardized coefficient; $\mathrm{SE}_{\mathrm{B}}$, standard error of the coefficient; $\beta$, standardized coefficient; $\mathrm{t}$, Student's t-test; $\mathrm{p}$, level of significance; $\mathrm{Cl}$, confidence interval. 


\section{Discussion}

The purpose of this study was to test MTM in explaining the intention for initiation and sustenance of CPAP/BiPAP adherence among newly diagnosed sleep apnea patients. The study found that all three constructs of the model namely behavioral confidence, changes in the physical environment and participatory dialogue in which the advantages outweigh the disadvantages were found to be significant predictors in explaining the starting of PAP therapy among newly diagnosed patients while controlling for their sleep study experience which was not statistically significant. The model explained $53.5 \%$ of the variance in intention for starting PAP therapy among newly diagnosed sleep apnea patients. Likewise, for the intention for maintaining PAP therapy among newly diagnosed sleep apnea patients all three constructs of MTM namely emotional transformation, changes in the social environment and practice for change were found to be statistically significant predictors after controlling for the sleep study experience which was not significant. The model explained $60.6 \%$ of the variance in the intention for maintaining PAP therapy among newly diagnosed sleep apnea patients. In previous literature psychosocial factors have been suggested for improving PAP therapy. ${ }^{7,16}$ Very few theorybased behavioral studies have been done to explain PAP adherence. A study using Health Belief Model was able to explain only $21.8 \%$ of the variance in CPAP adherence which is very low compared to the present study. ${ }^{17}$ Another study with social cognitive theory variables was able to predict only $11.5 \%$ of the variance and transtheoretical model constructs only $15.7 \%$ in CPAP adherence. ${ }^{19}$ This study is significant in this regard where it provides evidence and directions for reifying specific and precise constructs in educational and counseling interventions for newly diagnosed patients of sleep apnea and offers higher predictability than older behavioral theories.

The construct of behavioral confidence is very important in helping a patient to decide to start using PAP therapy. This construct is related to self-efficacy which has been supported by previous literature as important for CPAP adherence. ${ }^{17-19}$ This must be done despite the initial inconvenience and nasal problems that many respondents reported. The behavioral confidence to clean the equipment and to be able to use it while traveling is also vital. In counseling patients, small steps should be used to build this confidence and they need to be reassured that the problems that they are experiencing are transient and with time would go away. A recent intervention has used a related construct of self-efficacy in the SCIP-PA Trial. ${ }^{34}$ Behavioral confidence is a refined version of self-efficacy in which the source of confidence can even come from outside the self (such as from God, deity, powerful other, etc.) and is futuristic.

The construct of changes in the physical environment was also found to be statistically significant in this study to foster the initiation of PAP therapy. The cost of the equipment and access to it can potentially decrease the chances of its use. ${ }^{15,35}$ Health care providers in their counseling sessions must take time to explore if the availability of the equipment will be a potential problem and make attempts to work with the insurance companies and other means to help the patient in this regard.

The construct of participatory dialogue (in which advantages outweigh the disadvantages) was also found to be crucial in swaying the decisional balance of the patient in favor of its use. This is also supported from previous studies using Health Belief Model, Social Cognitive Theory, and Transtheoretical model ${ }^{17-19}$ Proximal advantages such as the ability to sleep well, not having snoring problem, having less daytime drowsiness, having less chances of getting into motor vehicle accidents, improved quality of life; and distal advantages such as decreased chances of getting into heart disease, hypertension, stroke must be explored in counseling sessions with the patients.

For adherence to PAP therapy, which is of vital significance in sleep apnea patients, the construct of emotional transformation was found to be significant in this study. ${ }^{8,9,34}$ No previous study has looked into this aspect where the patient can mobilize his or her negative emotions into a positive goal of adhering for so many hours of PAP therapy every night. Health care providers in their counseling session must take time to explore such motivation on part of the patient.

Another dimension for compliance with PAP therapy in this study was found to be practice for change that entails constant reflective action and active reflection on the behavior. This can be done by training the patient in keeping a daily record of his PAP usage by an app and then reflecting on ways this usage can be increased and regularized. Constant selfreinforcement by positive self-assertion by the patient also goes a long way in building this construct.

The final construct pertains to the changes in the social environment. Social support particularly spousal support has been found to be beneficial in promoting PAP adherence which was also confirmed in this study. ${ }^{36,37}$ In developing this construct social support such as from family 
members, friends, or health professionals must be mobilized. The health care provider can explore these sources with the patient and can also provide such support through regular personalized follow-up. So in essence, effective counseling interventions can be designed to improve adherence to PAP therapy using MTM which can help prioritize salient constructs thereby saving time in counseling and making it precise, efficient and effective.

\section{Limitations of the Study}

This study had some limitations that need to be discussed. First, as mentioned earlier, the cross-sectional design used in this study was a snapshot in time where information on both the independent and dependent variables was collected at the same time. Hence, the temporality of association cannot be established by this study. However, it is worth noting that MTM has been used in a longitudinal randomized controlled trial and the directionality of association of its constructs has been found to withstand the empirical testing. ${ }^{27}$ The other limitation of the study was that it relied on subjective self-reporting and used a proxy measure of actual compliance in the form of asking the respondents about their intent to initiate and sustain usage instead of actual usage. Since this study was about psychosocial attitudes and objective measurement is not possible so this was considered as the best possible approach. Future studies can utilize longitudinal designs and measure actual adherence. Another limitation was that the instrumentation used in the study had acceptable face validity, content validity, construct validity and internal consistency reliability but stability was not established. Future studies should consider doing test-retest reliability on the instrument to ensure that the instrument is stable over time. Furthermore, no attempt was made to collect information about different types of PAPs used by the participants, which might have affected the findings of this study, if the type of PAP was included in the analyses as a covariate. Finally, even though we did power analysis, the sample size was relatively small which limits generalizability of the results.

\section{Conclusions}

This study empirically tested salient psychosocial factors based on MTM in their ability to explain the intention for initiation and sustenance of PAP therapy. The model was found to be promising with all its constructs being significant in both the models of intentions for starting PAP therapy and maintaining PAP therapy. Brief and precise interventions based on reifying the six constructs of MTM may be implemented and tested by health care providers in sleep medicine practice settings. Such efforts may go a long way in improving adherence to PAP therapy.

\section{Acknowledgments}

We would like to thank the participants of this study and our institutions for their support.

\section{Disclosure}

The study was conducted at the lab of the second author. The authors report no other potential conflicts of interest for this work.

\section{References}

1. Gould GA, Whyte KF, Rhind GB, et al. The sleep hypopnea syndrome. Am Rev Respir Dis. 1988;137(4):895-898. doi:10.1164/ ajrccm/137.4.895

2. Gottlieb DJ, Punjabi NM. Diagnosis and management of obstructive sleep apnea: a review. JAMA. 2020;323(14):1389-1400. doi:10.1001/ jama.2020.3514

3. Young T, Peppard PE, Gottlieb DJ. Epidemiology of obstructive sleep apnea: a population health perspective. Am J Respir Crit Care Med. 2002;165(9):1217-1239. doi:10.1164/rccm.2109080

4. Punjabi NM. The epidemiology of adult obstructive sleep apnea. Proc Am Thorac Soc. 2008;5(2):136-143. doi:10.1513/pats.200709$155 \mathrm{MG}$

5. Epstein LJ, Kristo D, Strollo PJ Jr, et al. Adult Obstructive Sleep Apnea Task Force of the American Academy of Sleep Medicine. Clinical guideline for the evaluation, management and long-term care of obstructive sleep apnea in adults. J Clin Sleep Med. 2009;5 (3):263-276.

6. Gay P, Weaver T, Loube D, Iber C. Evaluation of positive airway pressure treatment for sleep related breathing disorders in adults. Sleep. 2006;29(3):381-401. doi:10.1093/sleep/29.3.381

7. Sawyer AM, Gooneratne NS, Marcus CL, et al. A systematic review of CPAP adherence across age groups: clinical and empiric insights for developing CPAP adherence interventions. Sleep Med Rev. 2011;15(6):343-356. doi:10.1016/j.smrv.2011.01.003

8. O'Donnell AR, Bjornson CL, Bohn SG, Kirk VG. Compliance rates in children using noninvasive continuous positive airway pressure. Sleep. 2006;29(5):651-658.

9. Engleman HM, Martin SE, Douglas NJ. Compliance with CPAP therapy in patients with the sleep apnoea/hypopnoea syndrome. Thorax. 1994;49(3):263-266. doi:10.1136/thx.49.3.263

10. Rotenberg BW, Murariu D, Pang KP. Trends in CPAP adherence over twenty years of data collection: a flattened curve. J Otolaryngol Head Neck Surg. 2016;45(1):43. doi:10.1186/s40463-016-0156-0

11. Morris LG, Setlur J, Burschtin OE, et al. Acoustic rhinometry predicts tolerance of nasal continuous positive airway pressure: a pilot study. Am J Rhinol. 2006;20(2):133-137. doi:10.1177/ 194589240602000202

12. Riachy M, Najem S, Iskandar M, et al. Factors predicting CPAP adherence in obstructive sleep apnea syndrome. Sleep Breath. 2017;21(2):295-302. doi:10.1007/s11325-016-1408-y

13. Platt AB, Field SH, Asch DA, et al. Neighborhood of residence is associated with daily adherence to CPAP therapy. Sleep. 2009;32 (6):799-806. 
14. Lewis KE, Seale L, Bartle IE, Watkins AJ, Ebden P. Early predictors of CPAP use for the treatment of obstructive sleep apnea. Sleep. 2004;27(1):134-138. doi:10.1093/sleep/27.1.134

15. Goyal A, Agarwal N, Pakhare A. Barriers to CPAP use in India: an exploratory study. J Clin Sleep Med. 2017;13(12):1385-1394. doi: $10.5664 / \mathrm{jcsm} .6830$

16. Hoy CJ, Vennelle M, Kingshott RN, Engleman HM, Douglas NJ. Can intensive support improve continuous positive airway pressure use in patients with the sleep apnea/hypopnea syndrome? Am J Respir Crit Care Med. 1999;159(4):1096-1100. doi:10.1164 ajrccm.159.4.9808008

17. Olsen S, Smith S, Oei T, Douglas J. Health belief model predicts adherence to CPAP before experience with CPAP. Eur Respir J. 2008;32(3):710-717. doi:10.1183/09031936.00127507

18. Aloia MS, Arnedt JT, Stepnowsky C, Hecht J, Borrelli B. Predicting treatment adherence in obstructive sleep apnea using principles of behavior change. $J$ Clin Sleep Med. 2005;1(04):346-353. doi: $10.5664 /$ jcsm. 26359

19. Stepnowsky CJ, Marler MR, Palau J, Brooks JA. Social-cognitive correlates of CPAP adherence in experienced users. Sleep Med. 2006;7(4):350-356. doi:10.1016/j.sleep.2005.11.004

20. Bakker JP, Weaver TE, Parthasarathy S, Aloia MS. Adherence to CPAP: what should we be aiming for, and how can we get there? Chest. 2019;155(6):1272-1287. doi:10.1016/j.chest.2019.01.012

21. Sharma M. Multi-theory model (MTM) for health behavior change. Webmedcentral Behav. 2015;6(9):WMC004982.

22. Sharma M. Theoretical Foundations of Health Education and Health Promotion. 3rd ed. Burlington, MA: Jones \& Bartlett; 2017.

23. Asare M, Agyei-Baffour P, Lanning BA, et al. Multi-theory model and predictors of likelihood of accepting the series of HPV vaccination: a cross-sectional study among Ghanaian adolescents. Int J Environ Res Public Health. 2020;17(2):571. doi:10.3390/ ijerph 17020571

24. Dokun-Mowete CA, Sharma M, Beatty F. Using multi-theory model to predict low salt intake among Nigerian adults with hypertension. Int $Q$ Community Health Educ. 2019;39(4):245-255. doi:10.1177/ 0272684X18821308

25. Hayes T, Nahar VK, Sharma M. Predicting physical activity behavior in African American females: using multi theory model. J Res Health Sci. 2018;18(2):e00410.

26. Sharma M, Stephens PM, Nahar VK, et al. Using multi-theory model to predict initiation and sustenance of fruit and vegetable consumption among college students. J Am Osteopath Assoc. 2018;118 (8):507-517. doi:10.7556/jaoa.2018.119
27. Hayes T, Sharma M, Shahbazi M, et al. The evaluation of a fourth-generation multi-theory model (MTM) based intervention to initiate and sustain physical activity. Health Promot Perspect. 2019;9 (1):13-23. doi:10.15171/hpp.2019.02

28. Brown L, Sharma M, Leggett S, et al. Efficacy testing of the SAVOR (Sisters Adding Fruits and Vegetables for Optimal Results) intervention among African American women: a randomized controlled trial. Health Promot Perspect. 2020;10(3):270-280. doi:10.34172/ hpp. 2020.41

29. Bashirian S, Barati M, Sharma M, Abasi H, Karami M. Predicting to reduce water pipe smoking in male adolescents: using multi theory model (MTM). J Subst. Use. 2020;25(1):50-55. doi:10.1080/ 14659891.2019.1664653

30. Luyster FS, Dunbar-Jacob J, Aloia MS, et al. Patient and partner experiences with obstructive sleep apnea and CPAP treatment: a qualitative analysis. Behav Sleep Med. 2016;14(1):67-84. doi:10.1080/15402002.2014.946597

31. Wang Y, Gao W, Sun M, Chen B. Adherence to CPAP in patients with obstructive sleep apnea in a Chinese population. Respir Care. 2012;57(2):238-243. doi:10.4187/respcare.01136

32. Faul F, Erdfelder E, Lang AG, Buchner A. G* Power 3: a flexible statistical power analysis program for the social, behavioral, and biomedical sciences. Behav Res Methods. 2007;39(2):175-191. doi:10.3758/BF03193146

33. Sharma M, Petosa RL. Measurement and Evaluation for Health Educators. Burlington, MA: Jones \& Bartlett Learning; 2014:126-139.

34. Sawyer AM, King TS, Weaver TE, et al. A tailored intervention for PAP adherence: the SCIP-PA Trial. Sleep Med Rev. 2019;17 (1):49-69.

35. Rezaie L, Phillips D, Khazaie H. Barriers to acceptance and adherence to continuous positive airway pressure therapy in patients with obstructive sleep apnea: a report from Kermanshah province, western Iran. Patient Prefer Adherence. 2018;12:1299-1304. doi:10.2147/ PPA.S165905

36. Ye L, Malhotra A, Kayser K, et al. Spousal involvement and CPAP adherence: a dyadic perspective. Sleep Med Rev. 2015;19:67-74. doi:10.1016/j.smrv.2014.04.005

37. Mehrtash M, Bakker JP, Ayas N. Predictors of continuous positive airway pressure adherence in patients with obstructive sleep apnea. Lung. 2019;197(2):115-121. doi:10.1007/s00408-018-00193-1

\section{Publish your work in this journal}

Nature and Science of Sleep is an international, peer-reviewed, open access journal covering all aspects of sleep science and sleep medicine, including the neurophysiology and functions of sleep, the genetics of sleep, sleep and society, biological rhythms, dreaming, sleep disorders and therapy, and strategies to optimize healthy sleep
The manuscript management system is completely online and includes a very quick and fair peer-review system, which is all easy to use. Visit http://www.dovepress.com/testimonials.php to read real quotes from published authors. 